АРТИЩЕВА Л. В.

ПОЛОВОЗРАСТНЫЕ ОСОБЕННОСТИ СОДЕРЖАНИЯ СУБЪЕКТИВНОГО ОПЫТА ПСИХИЧЕСКИХ СОСТОЯНИЙ...

РоссиЙскИй пСИХОЛоГИЧЕСКИЙ ЖУРнАл, 2019, Т. 16, № 4, 5-21. doi: 10.21702/rpj.2019.4.1

КОРРЕКЦИОННАЯ ПСИХОЛОГИЯ

УДК 159.9.072 doi: 10.21702/rpj.2019.4.1

Оригинальная научная статья

\title{
Половозрастные особенности содержания субъективного опыта психических состояний детей с нарушениями в развитии
}

\author{
Лира В. Артищева \\ Казанский (Приволжский) федеральный университет, г. Казань, Российская Федерация \\ E-mail: ladylira2013@yandex.ru \\ ORCID ID: https://orcid.org/0000-0002-9572-1307
}

\begin{abstract}
Аннотация
Введение. Целью исследования яви^ось изучение половозрастных особенностей в структуре субъективного опыта психических состояний Аетей с Аефицитарным развитием.

Метолы. ИсслеАовался сУбъективный опЫт психических состояний: раАости, гнева, спокойствия. Аети ретроспективно и перспективно описывали психические состояния. МетоАом контент-анализа текстов были вылелены смысловые еАиницы, высчитывалась частота их встречаемости.

Результаты. Субъективный опыт психических состояний Аетей с нарушениями в развитии имеет солержательную специфиику в зависимости от пола, возраста. Субъективный опыт некоторых психических состояний может иметь схожее солержание у мальчиков и Аевочек. Аетский церебральный паралич: субъективный опыт психических состояний мальчиков м^алшего возраста более выражен, солержательнее, чем у левочек млалшего возраста и У мальчиков-поАростков. У Аевочек к поАростковому возрасту опЫт переживаний состояний значимо обогащается. В поАростковом возрасте субъективный опыт состояний имеет разную выраженность в зависимости от пола и психического состояния. Тяжелые нарушения речи: у мальчиков м^алшего возраста субъективный опыт состояния раАости значимо более выражен, чем у мальчиков-полростков. Опыт спокойствия у мальчиков имеет схожесть в соАержании, а у левочек млалшего возраста значительно богаче прелставлен, чем у мальчиков того же возраста. Субъективный опыт психических состояний, проецируясь в будущее, трансорормируется, теряя некоторые содержательные компоненты.

ОбсужАение результатов. Изучение субъективного опыта психических состояний Аетей с Аефрицитарным развитием расширяет формат имеющихся исслеАований в области психологии психических состояний. Впервые раскрывается специфика опыта психических состояний Аетей с различной нозологией. Результаты Аанного исслеАования не противоречат имеющимся Аанным о психических состояниях Аетей школьного возраста, приведенным ранее А. О. Прохоровым.
\end{abstract}

\section{КАючевые слова}

субъективный опыт, опыт переживания, опыт состояний, психические состояния, Аесрицитарное развитие, Аетский церебральный паралич, тяжелые нарушения речи, половые особенности, возрастные особенности, временной континуум 
АРТИЩЕВА Л. В.

ПОЛОВОЗРАСТНЫЕ ОСОБЕННОСТИ СОДЕРЖАНИЯ СУБЪЕКТИВНОГО ОПЫТА ПСИХИЧЕСКИХ СОСТОЯНИЙ...

Российский психологИчЕский жУРнАл, 2019, Т. 16, № 4, 5-21. doi: 10.21702/rpj.2019.4.1

КОРРЕКЦИОННАЯ ПСИХОЛОГИЯ

\section{Основные положения}

> субъективный опыт психических состояний имеет общее в своем содержании и специфичное, в зависимости от пола, возраста в различных нозологических группах Аетей;

> субъективный опыт состояний соАержит регулятивный компонент, что говорит о высокой степени осознанности состояния некоторыми Аетьми, понимания механизмов саморегуляции; > субъективный опыт состояний Аетей млалшего возраста определяется наибольшей соАержательностью. Опыт состояний в м^алшем возрасте у мальчиков прелставлен богаче, чем у девочек. Субъективный опыт Аевочек к полростковому возрасту насыщается эмоционально-чувственными характеристиками;

> субъективный опыт психических состояний трансорормируется во временном континууме, что позволяет прогнозировать Аинамику состояний Аетей и вылелять сквозные смысловые еАиницы Аля их встраивания в процессе регуляции.

\section{Для цитирования}

Артищева, Л.В. (2019). Половозрастные особенности содержания субъективного опыта психических состояний детей с нарушениями в развитии. Российский психологический журнал, 16(4), 5-21. doi: 10.21702/rpj.2019.4.1

Дата получения рукописи: 15.12 .2019

Дата окончания рецензирования: 27.01.2020

Дата принятия к публикации: 30.01.2020

\section{Введение}

\section{Субъективный опыт психических состояний}

Психические состояния переживаются человеком, отражаясь в его сознании и фиксируясь в структурах памяти. Динамика психических состояний является достаточно сложным и комплексным закономерным процессом, при котором усложняется и обогащается эмоциональная сфера ребенка в контексте его общей социализации (Изотова и Никифорова, 2004). Психические состояния отрицательной модальности (гнев, страх, тревога, тоска и др.), поведение, детерминированное ими (плаксивость, уход в себя, зажатость и т. п.), выступают в качестве основных признаков нарушения психического развития детей, сказываясь на их социальной адаптации и личностном становлении (Изард, 2010).

События, ситуации прошлого и связанные с ними состояния хранятся в памяти, образуя содержание субъективного опыта. Психические состояния фиксируются в субъективном опыте человека в виде образа, который имеет определенную структуру, содержит информацию об интенсивности и содержательности состояний. То есть опыт представляет собой пространственно-временную схему состояний (Прохоров, 2008, 2011, 2012, 2013), является основанием для индивидуальных различий в познавательной деятельности (Холодная, 2002, 2004). Опыт переживания психических состояний позволяет идентифицировать свои состояния и состояния других (Артищева, 2018; Artishcheva, 2018, 2019), что обеспечивает личностное и социальное взаимодействие людей. Субъективный опыт психических состояний формируется, обогащается и трансформируется в течение всей жизни человека, что может быть обусловлено личностными особенностями, возрастными и половыми различиями. Опыт представляет собой 
АРТИЩЕВА Л. В.

ПОЛОВОЗРАСТНЫЕ ОСОБЕННОСТИ СОДЕРЖАНИЯ СУБЪЕКТИВНОГО ОПЫТА ПСИХИЧЕСКИХ СОСТОЯНИЙ...

РосСИйскИй пСИХОЛоГИЧЕСКИЙ ЖУРнАл, 2019, Т. 16, № 4, 5-21. doi: 10.21702/rpj.2019.4.1

КОРРЕКЦИОННАЯ ПСИХОЛОГИЯ

знание причин эмоций и психических состояний (Barrett, Mesquita, Ochsner, \& Gross, 2007).

Незрелость эмоциональной сферы, свойственная детям с дефицитарным развитием, обусловливает поведенческие и эмоциональные проявления (ситуативность, нестабильность, нестойкость). В связи с этим очевидно, что и субъективный опыт психических состояний детей с дефицитарным развитием будет обедненным и отражать специфику нарушения.

\section{Эмоциональная сфера детей с нарушениями опорно-двигательного аппарата}

Дети с нарушениями опорно-двигательного аппарата (далее НОДА) чаще всего имеют незрелую эмоционально-волевую сферу. В основе их поступков обычно лежат эмоции удовольствия и сиюминутные желания, что приводит к эгоцентричности, неспособности сочетать свои и чужие интересы, подчиняться правилам и требованиям коллектива (Зайцева и Красиков, 2015). Такие дети обычно бывают беспокойными, расторможенными и суетливыми, с частой сменой настроения (Гарбузов, 1994; Ильин, 2013).

Отмечается повышенная ранимость, когда ребенок осознает свою физическую неполноценность, что детерминирует возникновение у них опасений оказаться смешными, и что еще более осложняет их социализацию (Кузнецова, Переслени и Солнцева, 2002). При нарушении опорно-двигательного аппарата, когда ребенок переживает свой двигательный дефект, вторичным нарушением могут выступать невротические и психотические реакции, т. е. эмоциональная сфера (Саморокова, 2015).

Наиболее остро физический недостаток переживается в подростковый и юношеский периоды. Физическая недостаточность может мобилизовать подростка на борьбу с болезнью, своей неполноценностью, чтобы найти себя в социуме. Но бывает, что переживания становятся центральными в жизни, уводя подростка от активного включения в социальную жизнь (Кузнецова и др., 2002).

Хроническое состояние конфликта между реальными возможностями и ожиданиями детей с НОДА приводит к постоянному чувству тревоги, напряжения, беспокойства. Тревожность таких детей приводит к робости, агрессивности и страхам, порой даже к безразличию, доходящей до апатии (Саморокова, 2015).

Переживания детей и подростков с ДЦП продиктованы имеющимися нарушениями в развитии. Осознание своей неполноценности обусловливает широкий спектр состояний.

\section{Эмоциональная сфера детей с тяжелыми нарушениями речи}

Нарушения речи обусловливают специфику развития детей. Они оказываются в условиях социальной депривации, что затрудняет усвоение социального опыта; искажается развитие эмоциональной сферы, а вместе с ней страдает и эмоциональная лексика (Кондратенко, 2002; Дубрынина и Боброва, 2017; Грибова, 1995). Такие дети испытывают затруднения в осознании своих и чужих эмоций, в дифференциации психических состояний, склонны к стрессовым состояниям, у них чаще доминирует отрицательный эмоциональный фон (Кондратенко, 2002; Шипицына и Волкова, 1993).

Они часто бывают раздражительными, неусидчивыми, возбудимыми, порой даже агрессивными, неуверенными в себе, обидчивыми и замкнутыми. При этом им свойственна быстрая переключаемость в переживаниях. Незрелость эмоционально-волевой сферы приводит к изменениям в личностной сфере и своеобразию поведения (Юрчук, 2008; Шкуркина, 2018; Лебединский, 2011). 
АРТИЩЕВА Л. В.

ПОЛОВОЗРАСТНЫЕ ОСОБЕННОСТИ СОДЕРЖАНИЯ СУБЪЕКТИВНОГО ОПЫТА ПСИХИЧЕСКИХ СОСТОЯНИЙ...

Российский психологИчЕский жУРнАл, 2019, Т. 16, № 4, 5-21. doi: 10.21702/rpj.2019.4.1

КОРРЕКЦИОННАЯ ПСИХОЛОГИЯ

Наличие проблем в эмоциональной сфере детей с дефицитарным развитием определяет стратегию коррекции и обучения таких детей эмоциональной грамотности или компетенции (Barnfather \& Amod, 2012; Kremenitzer, 2005), подразумевающую знания об эмоциях и психических состояниях (Izard et al., 2001). Эмоциональная неграмотность детей с нарушениями в развитии определяется не только сложностью в выражении своих эмоций, их понимании и идентификации, но и личностными особенностями ребенка, условиями его воспитания. Ученые показали, что у детей с ограниченными возможностями здоровья, воспитывающихся у родителей с сенсорными нарушениями, уровень эмпатии и сопереживания выше (Eden, Romi, \& Braun Aviyashar, 2017; Duvdevany, Moin, \& Yahav, 2007).

Идентификация эмоций и психических состояний, их узнавание у себя и у других людей позволяют выстраивать положительное социальное взаимодействие, определяют успешность коммуникации, снижают проблемное поведение (Izard et al., 2001). Очевидна необходимость развития эмоциональной грамотности, навыка узнавать, осознавать и понимать психические состояния, что является возможным при наличии сформированного богатого опыта психических состояний.

Научная значимость результатов исследования объясняется тем, что изучение одного из аспектов субъективного опыта, связанного с психическими состояниями, их динамикой, интенсивностью и структурной организацией, позволит расширить границы понимания категории субъективного опыта в психологической науке. Также результаты исследования дополнят имеющийся научный задел в дефектологии. В рамках дефектологических наук исследуется, в основном, эмоционально-волевая сфера лиц с ограниченными возможностями здоровья. Раскрыта специфика эмоциональных состояний у детей в зависимости от нозологии. Очень фрагментарно представлены данные об идентификации психических состояний и эмоций детьми с различными нарушениями. Поэтому значимость изучения содержания субъективного опыта психических состояний детей и подростков с нарушениями в развитии в различных возрастных группах и с выделением половых особенностей для дефектологической науки не вызывает сомнений.

Практическая значимость. Специфика субъективного опыта психических состояний детей с нарушениями в развитии не изучена, но является значимой для успешной адаптации и социализации детей, важной для формирования навыков общения и взаимодействия с окружающими, для развития эмоционально-волевой сферы.

\section{Методы}

\section{Характеристика объекта}

Экспериментальная база исследования субъективного опыта - дети (7-11 лет, по 10-12 человек) и подростки (13-14 лет, по 10-13 человек) с нарушениями в развитии (тяжелые нарушения речи, детский церебральный паралич), с сохранным интеллектом.

\section{Методики и методы исследования}

Структурные компоненты субъективного опыта психических состояний детей и подростков определялись с использованием метода самоотчетов и контент-анализом текстов. Нами было выбрано три типичных психических состояния, часто переживаемых и знакомых детям и подросткам: радость, гнев, спокойствие. Данные состояния являются разномодальными (положительные, отрицательные) и с разным уровнем психической активности (высокий, средний). 
АРТИЩЕВА Л. В.

ПОЛОВОЗРАСТНЫЕ ОСОБЕННОСТИ СОДЕРЖАНИЯ СУБЪЕКТИВНОГО ОПЫТА ПСИХИЧЕСКИХ СОСТОЯНИЙ...

РосСИйскИй пСИХОЛоГИЧЕСКИЙ ЖУРнАл, 2019, Т. 16, № 4, 5-21. doi: 10.21702/rpj.2019.4.1

КОРРЕКЦИОННАЯ ПСИХОЛОГИЯ

\section{Ход исследования}

Исследовался субъективный опыт психических состояний - радости, гнева, спокойствия. Испытуемые ретроспективно и перспективно описывали свои психические состояния в свободной форме. На первом этапе испытуемые описывали психические состояния, пережитые в прошлом. Инструкция была следующая: «Вспомните, как Вы переживали радость (гнев, спокойствие) в прошлом, с какими событиями было связано, что Вы чувствовали, как проявлялась радость (гнев, спокойствие). Опишите как можно полно состояние».

На втором этапе описывали предвосхищения переживаний психических состояний в будущем. Инструкция: «Как Вы думаете, как Вы будете переживать радость (гнев, спокойствие) в будущем, с какими событиями будет связано, как будет проявляться радость (гнев, спокойствие)? Опишите как можно полно состояние в будущем».

Ответы испытуемых были обработаны экспертной группой при помощи контент-анализа. Единицей анализа были слова и словосочетания, которые выражали определенные значения, эмпирические индикаторы каждой смысловой единицы отражены в таблице 1. Далее высчитывалась частота встречаемости (упоминания) каждой смысловой единицы в текстах респондентов, что позволило определить наполненность и содержание субъективного опыта. Для выявления различий в выраженности показателей субъективного опыта психических состояний использовался t-критерий Стьюдента. Данные обрабатывались в программе SPPS- 17.

Исследовались группы, выделенные по половому и возрастному признакам в рамках одной нозологии, и нозологические группы в рамках одного возраста и одного пола. Выявляя чаще встречаемые смысловые единицы в самоотчетах испытуемых каждой выделенной подгруппы, мы тем самым определяли основное структурное содержание субъективного опыта психических состояний.

Цель - изучить специфику содержания субъективного опыта психических состояний детей с нарушениями речи и опорно-двигательного аппарата (одна нозологическая группа - дефицитарное развитие), выявить половые и возрастные особенности в наполненности субъективного опыта состояний.

\section{Задачи:}

1. Провести исследование, направленное на изучение субъективного опыта разномодальных психических состояний, имеющих различную степень психической активности.

2. Выявить специфику содержания субъективного опыта психических состояний в зависимости от возраста, пола, нозологии.

3. Выделить ядерные и периферические слои субъективного опыта психических состояний.

\section{Результаты}

Для выделения показателей, составляющих субъективный опыт психических состояний, тексты были поделены на смысловые единицы. Раскроем содержание данных единиц, т. е. их эмпирические индикаторы (табл. 1).

Выделенные смысловые единицы относятся к различным категориям. Дети и подростки с нарушениями в развитии описывают психические состояния, переживаемые в прошлом и в ожидаемом будущем, через указание причин состояний, через внешние маркеры, например, общение и единение с кем-либо. Раскрывают состояния через свое поведение, реакции, виды деятельности и активности. Но также в опыте встречаются внутренние маркеры, относящиеся 
АРТИЩЕВА Л. В.

ПОЛОВОЗРАСТНЫЕ ОСОБЕННОСТИ СОДЕРЖАНИЯ СУБЪЕКТИВНОГО ОПЫТА ПСИХИЧЕСКИХ СОСТОЯНИЙ...

Российский психологИческий жУРнАл, 2019, Т. 16, № 4, 5-21. doi: 10.21702/rpj.2019.4.1

КОРРЕКЦИОННАЯ ПСИХОЛОГИЯ

к миру их чувств и переживаний, оценочным суждениям и размышлениям. Особое внимание хочется уделить элементам регуляции и преодоления проблем. Некоторые дети в описаниях негативных состояний прибегают к регулятивным приемам, т. е. в субъективном опыте негативных психических состояний может встречаться и путь к их преодолению.

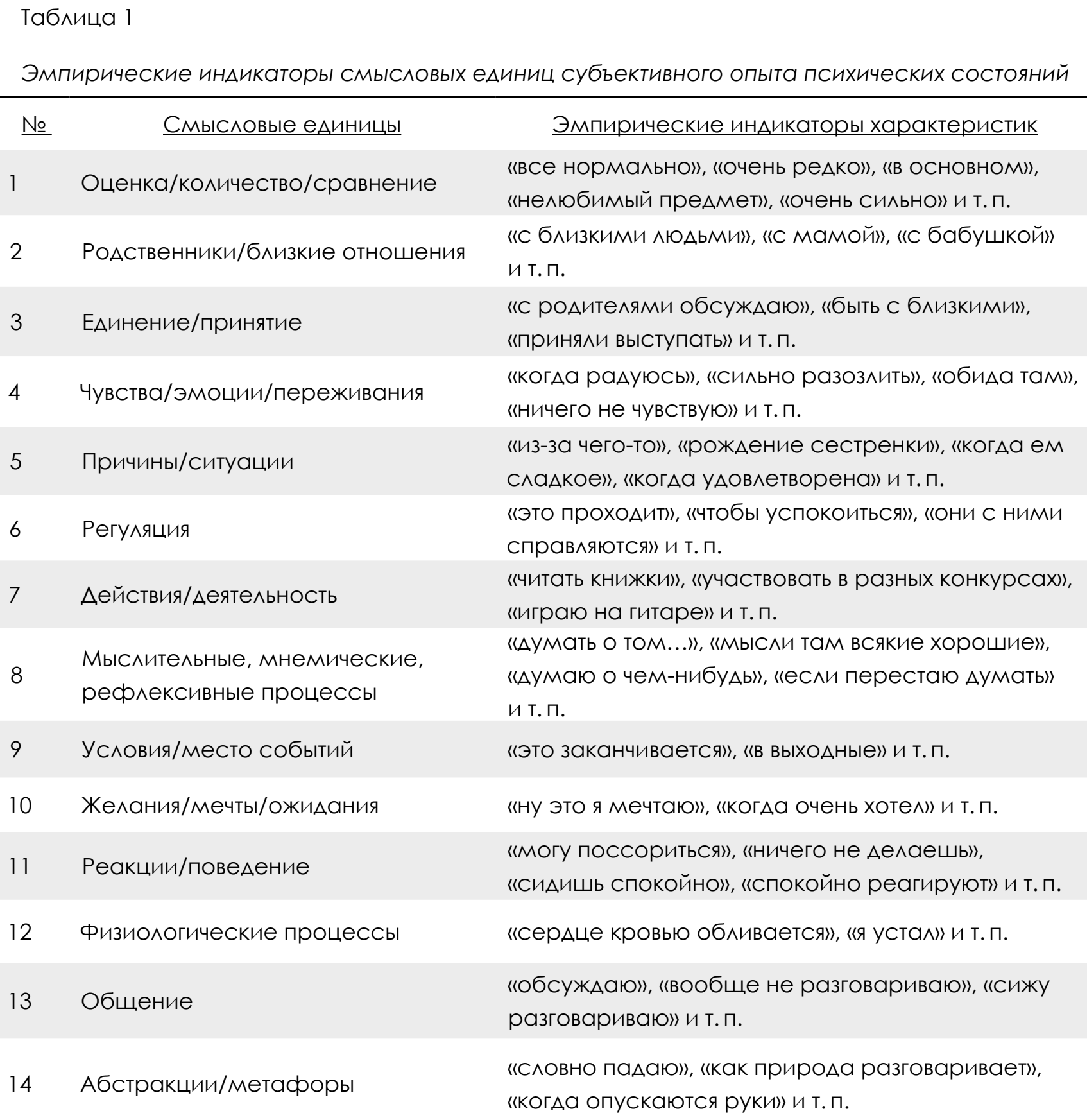

№ $\quad$ Смысловые единицы

1 Оценка/количество/сравнение

2 Родственники/близкие отношения

3 ЕАинение/принятие

4 Чувства/эмоции/переживания

5 Причины/ситуации

6 Регуляция

7 Аействия/Аеятельность

8 Мыслительные, мнемические, реорлексивные процессы

9 Условия/место событий

10 Желания/мечты/ожилания

11 Реакции/поведение

12 Физиологические процессь

13 Общение

14 Абстракции/метафроры

\section{Эмпирические индикаторы характеристик} «все нормально», «очень реАКо», «в основном», «нелюбимый преАмет», «очень сильно» и т. п. «С близкими АюАьми», «С мамой», «С бабушкой» И Т. п.

«с родителями обсужАаю», «быть с близкими», «приняАИ выступать» И т. п.

«КогАа раАуюсь», «Си^ьно разозлить», «обиАа там», «ничего не чувствую» И т. п.

«из-за чего-то», «рожАение сестренки», «когАа ем с^аАКое», «КОГАа уАовлетворена» и т.п.

«Это прохоАИт», «ЧтобЫ УспокоИтьСя», «ОНИ С нИМИ справляются» и т. п.

«читать КнижкИ», «участвовать в разных конкурсах», «играю на гитаре» и т. п.

"Аумать о том....", «мысли там всякие хорошие», «Аумаю о чем-нибудь», «если перестаю Аумать» И т.п.

«это заканчивается», «в выходные» и т.п.

«ну это я мечтаю», «когАа очень хотел» и т. п.

«могу поссориться», «ничего не Аелаешь», «сиАишь спокойно», «спокойно реагируют» и т.п. «серлце кровью обливается», «я устал» и т. п. «обсужАаю», «вообще не разговариваю», «сижу разговариваю» и т. п.

«С^овно паАаю», «как природа разговаривает», «когАа опускаются руки» и т. п. 
АРТИЩЕВА Л. В.

ПОЛОВОЗРАСТНЫЕ ОСОБЕННОСТИ СОДЕРЖАНИЯ СУБЪЕКТИВНОГО ОПЫТА ПСИХИЧЕСКИХ СОСТОЯНИЙ...

РосСиЙский псИХологИЧЕСКИй ЖУРнАл, 2019, Т. 16, № 4, 5-21. doi: 10.21702/rpj.2019.4.1

КОРРЕКЦИОННАЯ ПСИХОЛОГИЯ

Путем анализа частоты встречаемости смысловых единиц, показателей субъективного опыта психических состояний, мы определим ядерные слои опыта и его периферию.

Дети младшего возраста с двигательными нарушениями. Анализируя половые особенности субъективного опыта психических состояний, мы получили следующее. Мальчики (7-10 и 13-14 лет) с ДЦП более полно раскрывают состояние радости, чем девочки этих возрастов. Их тексты содержат описание различных сторон переживания состояний с использованием большего числа смысловых единиц. Субъективный опыт состояний радости и гнева (состояния высокого уровня психической активности) у мальчиков младшего возраста содержит, в основном, оценочно-сравнительные характеристики («давно», «вроде все», «плохо» и пр.), описание действий и деятельности («пошли в кино», «делали уроки», «наругает» и пр.), условий или места событий («очень давно», «после уроков», «сейчас», «со школы домой» и пр.). В проекции будущего субъективный опыт данных состояний обедняется, т. е. описания состояний в будущем скуднее (меньше частота упоминания смысловых единиц). Но сохраняются ведущие компоненты, кроме указания места и условий событий, сопровождающих переживания. Субъективный опыт состояния спокойствия у мальчиков младшего возраста представлен эмоциональными характеристиками («спокоен», «рада становилась», «не злился» и пр.) и отражающими действия, деятельность («не наругает», «пятерку получил», «сказку включает»). В будущее спокойствие проецируется, в основном, с описанием действий и деятельности. Отметим, что элемент регуляции у некоторых мальчиков младшего возраста встречается в субъективном опыте гнева в проекции на будущее, т. е. они уже прогнозируют управление данным состоянием в будущем.

Субъективный опыт состояний девочек более разнообразный. У девочек младшего возраста опыт состояния радости представлен, в основном, описаниями эмоционально-чувственных переживаний («грустно», «весело», «горда» и пр.), причин и ситуаций, детерминирующих радость («происходит веселье», «к бабуле поехать», «в кино пошли» и пр.), а также характеристиками, отражающими близкие отношения и родственные связи («к бабуле поехать», «мы с мамой», «с Ралиной» и пр.), действия и деятельность («пошли в кино», «плавала», «сидела дома» и пр.). В проекции на будущее субъективный опыт радости у девочек редуцируется, в качестве ведущего компонента сохраняется лишь описание действий и деятельности, но усиливается оценочно-сравнительными единицами. Субъективный опыт состояния гнева представлен меньшим числом смысловых единиц, среди них чаще встречаемые оценочно-сравнительные и эмоционально-чувственные («обидчивость», «расстройство», «злилась» и пр.) характеристики. В проекции будущего субъективный опыт изменяется, в нем увеличивается частота эмоционально-чувственных упоминаний («злюсь», «не буду испытывать гнев», «обиженная сидела» и пр.) и описание действий и деятельности («хулиганит», «кому-то портить, ломать» и пр.). Состояние спокойствия представлено в субъективном опыте, в основном, смысловыми единицами, которые раскрывают действия и деятельность («сидела», «плаваем», «рисую», «могла заниматься, чем хочу» и пр.), причины и ситуации («когда играю в игрушки», «когда делаю поделку» и пр.), детерминирующие данное состояние. Спокойствие проецируется в будущее, в основном, через оценочно-сравнительные характеристики и описание действий и деятельности. Указание на регуляцию своего состояния и поведения некоторые девочки младшего возраста отмечают только в проекции на будущее состояния гнева. В опыте одной из них встречается компонент, регулирующий состояние гнева («а потом все равно прощу»), у другой отмечается невозможность регуляции («вот не могу держать контроль»). 
АРТИЩЕВА Л. В.

ПОЛОВОЗРАСТНЫЕ ОСОБЕННОСТИ СОДЕРЖАНИЯ СУБЪЕКТИВНОГО ОПЫТА ПСИХИЧЕСКИХ СОСТОЯНИЙ...

Российский психологИчЕский жУРнАл, 2019, Т. 16, № 4, 5-21. doi: 10.21702/rpj.2019.4.1

КОРРЕКЦИОННАЯ ПСИХОЛОГИЯ

Дети подросткового возраста с двигательными нарушениями. Рассмотрим половые особенности субъективного опыта психических состояний у мальчиков и девочек среди подростков. Субъективный опыт радости у мальчиков-подростков представлен, в основном, оценочно-сравнительными характеристиками («иногда...», «всякие хорошие», «всё нормально» и пр.) и описаниями действий, деятельности («читать книги», «оказать помощь», «не надо ничего писать» и пр.). Проекция опыта состояния радости в будущее представлена, в основном, характеристикой, отражающей действия и деятельность. Субъективный опыт состояния гнева содержит оценочно-сравнительные характеристики и эмоции, чувства («раздраженный», «сильно злится», «я виноват» и пр.). Проецируется субъективный опыт гнева в будущее с меньшим числом смысловых единиц, из них чаще встречаемые характеристики сравнения и оценки, причины и ситуации («когда поссорюсь», «права заберут», «когда что-то не получается» и пр.), действия и деятельность («обидит», «что-то не выполняют», «не смогу водить» и пр.). Субъективный опыт состояния спокойствия содержит, в основном, описания действий и поступков («играю на гитаре», «мирно играет», «не остановишь» и пр.) и оценки, сравнения. В будущее опыт спокойствия проецируется, сохраняя данные смысловые единицы как чаще встречаемые. Регуляция состояний и поведения у мальчиков-подростков отражена в субъективном опыте гнева («это проходит», «гнев я стараюсь не выплескивать» и пр.) и спокойствия («в любых ситуациях сесть, попить чаек и успокоиться», «когда понимаешь, что ничего не сделать, не стоит ругаться»).

Субъективный опыт радости девочек-подростков содержит, в основном, эмоции, чувства («радость в душе», «счастливые моменты», «эмоциональное возбуждение») и экспрессивные проявления, реакции («у меня улыбка», «яркие глаза» и пр.). Девочки-подростки очень обедненно проецируют в будущее опыт переживания радости, его ведущим компонентом является оценочно-сравнительная характеристика. Гнев в их опыте представлен характеристиками сравнения и оценок («быстро проходит», «всегда» и пр.), чувственно-эмоциональными описаниями («держать в себе», «обидчивость», «ярость», «я виновата» и пр.). Проецируется субъективный опыт гнева у девочек-подростков измененным, но не обедненным смысловыми единицами; ведущей из них является характеристика, описывающая действия и деятельность. Содержание субъективного опыта спокойствия у девочек-подростков, в основном, представлено смысловыми единицами, отражающими оценки, сравнения и чувства, эмоции, переживания («отличное настроение», «спокойна»). В проекции на будущее субъективный опыт спокойствия ведущим компонентом сохраняет оценочно-сравнительную характеристику. Отметим, что регулятивный компонент у девочек-подростков встречается только в субъективном опыте гнева в континууме «прошлое - будущее».

Далее по такой же логике рассмотрим специфику субъективного опыта психических состояний детей с тяжелыми нарушениями речи.

Дети младиего возраста с тяжелыми нарушениями речи. Содержание опыта состояния радости у мальчиков младшего возраста представлено описанием действий, деятельности («это делали», «дарили подарки», «мама ругала» и пр.), отношениями с родственниками, близкими людьми («помогал маме», «Таня там была, старшая сестра» и пр.), причинами и ситуациями («когда не нужно за ней ухаживать», «что-то не разрешают», «радость от Нового года» и пр.). Проекция субъективного опыта радости в будущее у них раскрывается оценочными характеристиками, действиями, деятельностью. Субъективный опыт состояния гнева у мальчиков младшего возраста представлен описанием действий, деятельности («шел 
АРТИЩЕВА Л. В.

ПОЛОВОЗРАСТНЫЕ ОСОБЕННОСТИ СОДЕРЖАНИЯ СУБЪЕКТИВНОГО ОПЫТА ПСИХИЧЕСКИХ СОСТОЯНИЙ...

РосСИйскИй пСИХОЛоГИЧЕСКИЙ ЖУРнАл, 2019, Т. 16, № 4, 5-21. doi: 10.21702/rpj.2019.4.1

КОРРЕКЦИОННАЯ ПСИХОЛОГИЯ

попить», «дядя приезжает», «обижает меня», «драться» и пр.) и сравнением, оценкой. В будущее субъективный опыт состояния гнева проецируется с большим спектром чаще встречаемых характеристик. Мальчики младшего возраста указывают на эмоционально-чувственную сферу, оценочно-сравнительные характеристики состояния, отношения с родственниками и близкими, дают описание действий и деятельности. Субъективный опыт спокойствия и его проекция в будущее у мальчиков младшего возраста, в основном, представлены одинаковыми смысловыми единицами: оценочно-сравнительной («все хорошо», «так удобнее» и пр.), эмоционально-чувственной («чувствую спокойно», «не бешусь», «внутри хороший» и пр.) и действиями, деятельностью («делать уроки», «не ругали», «помогать маме» и пр.). В субъективном опыте состояний гнева и спокойствия содержится регулятивная характеристика («когда держать себя можно», «держать гнев»).

Субъективный опыт состояния радости у девочек младшего возраста представлен, в основном, описанием оценок, сравнений, эмоций, чувств («любила лето», «грустно» и пр.) и действий, деятельности («приезжала бабушка», «в бассейне купались» и пр.). В будущее опыт состояния радости проецируется измененным, но также с большим числом смысловых единиц; наиболее часто встречаемые характеристики отражают действия, деятельность, родственные отношения, условия, место событий. Субъективный опыт состояния гнева у девочек младшего возраста представлен описаниями действий, деятельности («раскидываю вещи», «подруга обижала» и пр.), сравнительно-оценочными характеристиками. В проекции на будущее в субъективном опыте гнева сохраняется ведущий компонент, описывающий действия и деятельность; также часто встречаемой является характеристика, отражающая условия и место событий, связанных с данным переживанием. Состояние спокойствия в прошлом опыте у мальчиков раскрывается через действия («рисовать», «я готовлю», «сидела на лошадке» и пр.), чувства, эмоции. Проекция субъективного опыта спокойствия в будущее трансформируется и представлена описаниями действий, деятельности и родственных отношений. Отметим, что в субъективном опыте гнева и спокойствия содержится регулятивный компонент («успокаиваюсь, когда ложусь на кровать», «он успокаивал»), он же проецируется и в будущее в субъективном опыте спокойствия («я успокаиваюсь, когда делаю поделки», «дом будет успокаивать» и пр.).

Субъективный опыт состояния радости у мальчиков-подростков, в основном, содержит описания причин и ситуаций, связанных с данным состоянием («когда приезжал в интернат», «ничего не происходило», «в разных ситуациях» и пр.). В будущее опыт состояния радости проецируется редуцированным, т. е. с меньшей частотой встречаемости смысловых единиц, ведущей из которых является оценочно-сравнительный компонент. Субъективный опыт состояния гнева представлен, в основном, описанием действий («мама наказала», «не разрешила», «побежали встретиться» и пр.) и причин, ситуаций, вызвавших данное состояние («когда мама умерла», «потому что много задали» и пр.). Субъективный опыт гнева проецируется в будущее, в основном, с оценочно-сравнительными характеристиками и указанием причин, ситуаций, связанных с гневом. Состояние спокойствия в субъективном опыте мальчиков-подростков раскрывается чаще через оценочно-сравнительные характеристики и указание причин, ситуаций («ничего не происходило», «любая музыка», «папа купил смартфон» и пр.). В проекции на будущее опыт состояния спокойствия представлен обедненно, т.е. с меньшим числом смысловых единиц и с меньшей их встречаемостью. В будущем опыт спокойствия представлен, в основном, описанием причин, ситуаций, связанных с данным состоянием, и действий, деятельности. Регулятивный компонент встречается в субъективном 
АРТИЩЕВА Л. В.

ПОЛОВОЗРАСТНЫЕ ОСОБЕННОСТИ СОДЕРЖАНИЯ СУБЪЕКТИВНОГО ОПЫТА ПСИХИЧЕСКИХ СОСТОЯНИЙ...

Российский психологИчЕский жУРнАл, 2019, Т. 16, № 4, 5-21. doi: 10.21702/rpj.2019.4.1

КОРРЕКЦИОННАЯ ПСИХОЛОГИЯ

опыте гнева во всем временном континууме «прошлое - будущее» («дрался и чувствовал после этого успокоение», «буду стараться спокойно все принимать», «грущу, но успокаиваюсь» и пр.) и в опыте состояния спокойствия («еще успокаивало...»).

Сравним выраженность показателей субъективного опыта психических состояний радости, гнева, спокойствия между детьми младшего и подросткового возраста с нарушениями опорно-двигательного аппарата (табл. 2). В таблице 2 указаны лишь те показатели, которые имеют значимые различия в исследуемых группах.

\begin{tabular}{|c|c|c|c|}
\hline \multicolumn{4}{|c|}{$\begin{array}{l}\text { Таблица } 2 \\
\text { Значимость различий в выраженности содержательных } \\
\text { психических состояний Аетей с Аетским церебральным пс }\end{array}$} \\
\hline \multicolumn{4}{|c|}{ РаАость. Мальчики } \\
\hline & Средние & Значимость разАичий & Средние \\
\hline Смысловые единицы & $\frac{\text { значения. }}{\text { Аети }}$ & $\frac{\text { по †-критерию }}{\text { СтьюАента }}$ & $\begin{array}{l}\frac{\text { Значения. }}{\text { ПоАростки }} \\
\end{array}$ \\
\hline 1. Оценка/количество/сравнение & $\overline{4,4}$ & $\overline{p<0,001}$ & 1,8 \\
\hline 2. Ролственники / близкие отношения & 2,1 & $p<0,001$ & 0,6 \\
\hline 4. Чувства/эмоции/переживания & 2,1 & $\mathrm{p}<0,01$ & 1,2 \\
\hline 5. Причины/ситуации & 2 & $p<0,01$ & 1,1 \\
\hline 7. Аействия/Аеятельность & 3,3 & $p<0,001$ & 1,8 \\
\hline 9. Ус^овия / место событий & 2,7 & $p<0,001$ & 0,8 \\
\hline \multicolumn{4}{|c|}{ РаАОсть. Аевочки } \\
\hline 2. Родственники / близкие отношения & 1,2 & $p<0,01$ & 0 \\
\hline 5. Причины/ситуации & 1,3 & $p<0,05$ & 0,7 \\
\hline 9. Ус^овия / место событий & 0,2 & $p<0,05$ & 0,7 \\
\hline 11. Реакции/поведение & 0,7 & $p<0,05$ & 1,3 \\
\hline \multicolumn{4}{|c|}{ Гнев. Мальчики } \\
\hline 2. Родственники / близкие отношения & 1,6 & $p<0,001$ & 0 \\
\hline 5. Причины/ситуации & 2 & $\mathrm{p}<0,01$ & 0,9 \\
\hline 6. Регуляция & 0 & $p<0,05$ & 0,6 \\
\hline 7. Аействия/Аеятельность & 3,6 & $p<0,001$ & 1 \\
\hline 9. Условия / место событий & 2,3 & $p<0,001$ & 0,5 \\
\hline 10. Желания/мечты/ожилания & 0,1 & $p<0,05$ & 0,6 \\
\hline
\end{tabular}


АРТИщЕВА Л. В.

ПОЛОВОЗРАСТНЫЕ ОСОБЕННОСТИ СОДЕРЖАНИЯ СУБЪЕКТИВНОГО ОПЫТА ПСИХИЧЕСКИХ СОСТОЯНИЙ...

РоссийскИй псИХологИчЕСКИЙ ЖУРнАл, 2019, Т. 16, № 4, 5-21. doi: 10.21702/rpj.2019.4.1

КОРРЕКЦИОННАЯ ПСИХОЛОГИЯ

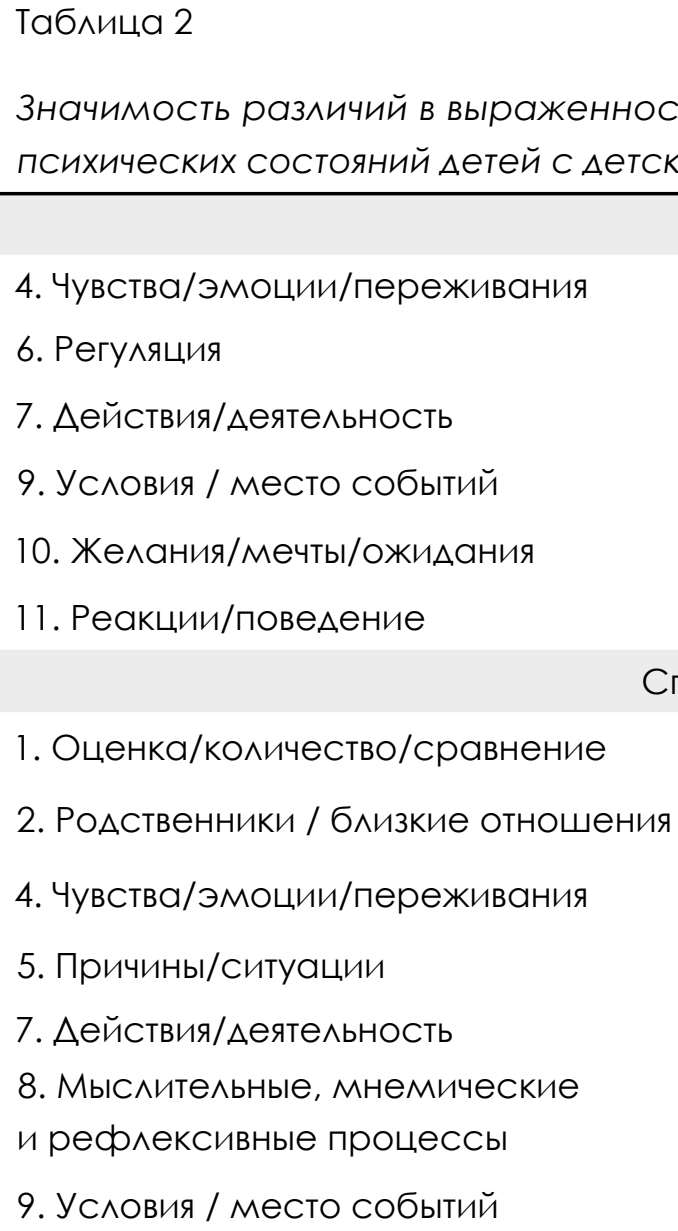

4. Чувства/эмоции/переживания

6. Регуляция

7. Аействия/Аеятельность

9. Условия / место событий

10. Желания/мечты/ожидания

11. Реакции/поведение

\section{1. Оценка/количество/сравнение}

2. Ролственники / близкие отношения

4. Чувства/эмоции/переживания

5. Причины/ситуации

7. Аействия/Аеятельность

8. Мыслительные, мнемические

и редрлексивные процессы

9. Условия / место событий

1

0,3

Спокойствие. Мальчики

$$
p<0,05
$$

1,1

$p<0,05$

$p<0,001$

0,8

$\mathrm{p}<0,01$

0,4

3,1

$p<0,001$

$$
p<0,01
$$

2

$\mathrm{p}<0,01$

Спокойствие. Аевочки
1. Оценка/количество/сравнение
4. Чувства/эмоции/переживания
7. Аействия/Аеятельность
8. Мыслительные, мнемические и редрлексивные процессы
9. Условия / место событий

0,5

$\mathrm{p}<0,01$

0,8

$p<0,001$

$\mathrm{p}<0,01$

$\mathrm{p}<0,05$

0,2

$\mathrm{p}<0,05$

0,7

Показатели субъективного опыта психических состояний - радость, гнев, спокойствие у мальчиков младшего возраста более выражены, т. е. их опыт содержательнее, чем у мальчиков-подростков. Можно выделить и сквозные характеристики субъективного опыта, которые значимо выражены в субъективном опыте каждого состояния. К ним относятся характеристики, отражающие родственные отношения, причины и ситуации, действия и деятельность, условие 
АРТИЩЕВА Л. В.

ПОЛОВОЗРАСТНЫЕ ОСОБЕННОСТИ СОДЕРЖАНИЯ СУБЪЕКТИВНОГО ОПЫТА ПСИХИЧЕСКИХ СОСТОЯНИЙ...

Российский психологИчЕский жУРнАл, 2019, Т. 16, № 4, 5-21. doi: 10.21702/rpj.2019.4.1

КОРРЕКЦИОННАЯ ПСИХОЛОГИЯ

и место событий. У девочек картина не так однозначна. Девочки младшего возраста в описаниях состояния радости, переживаемой в прошлом, чаще указывают на причины, ситуации, отношения с родственниками, которые детерминируют данное состояние. Но в опыте состояния радости девочек-подростков больший акцент делается на описании условий, событий и реакций, связанных с состоянием радости. Субъективный опыт состояния гнева у девочек подросткового возраста насыщеннее содержательными компонентами, чем у девочек младшего возраста. Характеристики субъективного опыта спокойствия, раскрывающие эмоционально-чувственную сферу, оценочно-сравнительный аспект, мыслительные, рефлексивные процессы, условия и место событий, значимо более представлены у девочек-подростков. А у девочек младшего возраста в субъективном опыте спокойствия более выражено описание действий и деятельности.

Далее сравним выраженность характеристик субъективного опыта психических состояний радости, гнева, спокойствия между мальчиками и девочками с нарушениями опорно-двигательного аппарата разных возрастов (табл. 3). В таблице 3 указаны лишь те показатели, которые имеют значимые различия в исследуемых группах.

Таблица 3

Значимость различий в выраженности содержательных компонентов субъективного опыта психических состояний Аетей с Аетским церебральным параличом (группы по половому признаку)

Ралость. Мальчики и Аевочки м^алшего возраста

\begin{tabular}{|c|c|}
\hline \multirow{2}{*}{ Cредние } & ЗначиМОсть \\
\hline & разАичий \\
\hline & по †-критерию \\
\hline & Стьюдента \\
\hline
\end{tabular}

1. Оценка/количество/сравнение

4,4

$p<0,001$

Cpедние

Смысловые еАиницы

2,1

$\mathrm{P}<0,01$ значения.

2. Родственники / близкие отношения

$\mathrm{P}<0,01$ $\triangle$ евочки

5. Причины/ситуации

$\mathrm{p}<0,01$

7. Аействия/Аеятельность

2,7

$\mathrm{p}<0,001$

9. Условия / место событий

Гнев. Мальчики и Аевочки м^адшего возраста

1. Оценка/количество/сравнение

2. Ролственники / близкие отношения

4. Чувства/эмоции/переживания

5. Причины/ситуации

7. Аействия/Аеятельность

9. Условия / место событий

11. Реакции/поведение

\section{2,4}

1,6

2,1

2

3,6

2,3

1,1 $p<0,01$

$p<0,01$

$p<0,01$

$P<0,001$

$p<0,001$

$p<0,001$

$p<0,01$
1,5

0,3

1

0,5

0,5

0,3

0,3 
АРТИщЕВА Л. В.

ПОЛОВОЗРАСТНЫЕ ОСОБЕННОСТИ СОДЕРЖАНИЯ СУБЪЕКТИВНОГО ОПЫТА ПСИХИЧЕСКИХ СОСТОЯНИЙ...

РоссийскИй псИХологИчЕСКИЙ ЖУРнАл, 2019, Т. 16, № 4, 5-21. doi: 10.21702/rpj.2019.4.1

КОРРЕКЦИОННАЯ ПСИХОЛОГИЯ

\section{Таблица 3}

Значимость различий в выраженности содержательных компонентов субъективного опыта психических состояний Аетей с Аетским церебральным параличом (группы по половому признаку)

Спокойствие. Мальчики и Аевочки млалшего возраста

$\begin{array}{lccc}\text { 1. Оценка/количество/сравнение } & 1,9 & \mathrm{p}<0,01 & 0,5 \\ \text { 4. Чувства/эмоции/переживания } & 2,6 & \mathrm{p}<0,001 & 0,8 \\ \text { 6. Регуляция } & 0,7 & \mathrm{p}<0,05 & 0 \\ \text { 7. Аействия/Аеятельность } & 3,1 & \mathrm{p}<0,01 & 2,3 \\ \text { 9. Условия/ место событий } & 2 & \mathrm{p}<0,01 & 0,2 \\ \text { 11. Реакции/поведение } & 1,1 & \mathrm{p}<0,01 & 0\end{array}$

РаАость. Мальчики и Аевочки поАросткового возраста

1. Оценка/количество/сравнение

1,8

$\mathrm{p}<0,01$

0,5

2. Ролственники / близкие отношения

0,6

$p<0,05$

1

3. ЕАинение/принятие

0,6

$p<0,05$

4. Чувства/эмоции/переживания

1,2

$p<0,01$

7. Аействия/Аеятельность

1,8

$p<0,01$

0,6

$\mathrm{p}<0,05$

11. Реакции/поведение

$p<0,01$

12. Физиологические процессы

0

Гнев. Мальчики и Аевочки поАросткового возраста
1. Оценка/количество/сравнение
2,4
$\mathrm{p}<0,05$
1,7
2. Ролственники / близкие отношения
0
$P<0,05$
0,7
4. Чувства/эмоции/переживания
1,4
5. Причины/ситуации
0,9
$p<0,05$
2
9. Условия / место событий
0,5
$\mathrm{p}<0,05$
0,3
$\mathrm{p}<0,01$

Спокойствие. Мальчики и Аевочки полросткового возраста
4. Чувства/эмоции/переживания
0,8
$\mathrm{p}<0,001$
5. Причины/ситуации
0,4
6. Регуляция
0,7
$p<0,05$
1
11. Реакции/поведение
0,7
$p<0,05$
$p<0,05$
0

Субъективный опыт исследуемых психических состояний у мальчиков младшего возраста значимо более выражен по многим показателям, чем у девочек младшего возраста. Можно выделить и сквозные характеристики, которые имеют значимые различия в субъективном опыте каждого состояния. К ним относятся оценочно-сравнительный компонент, действия и деятельность, условие и место событий, детерминирующих или сопровождающих переживания разномодальных состояний. В подростковом возрасте выявлена иная специфика. 
АРТИЩЕВА Л. В.

ПОЛОВОЗРАСТНЫЕ ОСОБЕННОСТИ СОДЕРЖАНИЯ СУБЪЕКТИВНОГО ОПЫТА ПСИХИЧЕСКИХ СОСТОЯНИЙ...

Российский психологИчЕский ЖУРнАл, 2019, Т. 16, № 4, 5-21. doi: 10.21702/rpj.2019.4.1

КОРРЕКЦИОННАЯ ПСИХОЛОГИЯ

В субъективном опыте состояния радости мальчиков-подростков значимо более выражены смысловые единицы, отражающие единение, родственные отношения, действия и деятельность, оценку и сравнение. А у девочек-подростков субъективный опыт радости наиболее представлен описаниями эмоционально-чувственной сферы и реакций. У мальчиков подросткового возраста в субъективном опыте состояния гнева значимо выражены оценочно-сравнительный компонент и раскрытие причин, ситуаций, связанных с гневом. В субъективном опыте состояния гнева девочек-подростков наиболее представлены описания родственных отношений, чувств и переживаний, условий и места событий. Субъективный опыт состояния спокойствия тоже имеет разную выраженность, в зависимости от пола. Так, например, у девочек подросткового возраста в опыте спокойствия значимо выражены эмоционально-чувственная сфера и описание причин, ситуаций. А у мальчиков-подростков в опыте спокойствия более полно раскрываются реакции, детерминированные спокойствием, и регулятивный аспект.

Далее по аналогии провели анализ значимых различий в группе детей с тяжелыми нарушениями речи (в силу ограниченности объема статьи таблицу с критерием различий не указали).

Субъективный опыт состояния радости у мальчиков младшего возраста значимо выражен, чем у мальчиков-подростков. У последних лишь характеристика, раскрывающая причины и ситуации, связанные с радостью, больше представлена в субъективном опыте. Субъективный опыт гнева имеет различную выраженность, в зависимости от возраста. Так, в субъективном опыте гнева у мальчиков младшего возраста большую выраженность имеют показатели, раскрывающие ситуации и причины гнева, действия и деятельность, мыслительные и рефлексивные процессы. А у мальчиков подросткового возраста в опыте гнева значимо больше представлены родственные отношения и эмоционально-чувственная сфера. Субъективный опыт состояния спокойствия имеет минимальное число различий в выраженности смысловых единиц. Лишь оценочно-сравнительная характеристика больше выражена в опыте спокойствия мальчиков-подростков.

Субъективный опыт состояния спокойствия у девочек младшего возраста значимо содержательнее, чем у мальчиков того же возраста. А вот субъективный опыт состояния радости и гнева неоднозначно представлен. Девочки младшего возраста при описании состояния радости, переживаемого в прошлом, больший акцент делают на оценочно-сравнительном аспекте и эмоционально-чувственной сфере. А в опыте радости у мальчиков младшего возраста значимо выражены показатели, раскрывающие родственные отношения, причины и ситуации, действия и деятельность. В субъективном опыте состояния гнева девочек младшего возраста наиболее выражены описания родственных отношений и желаний, мечтаний. У мальчиков в субъективном опыте гнева более выражены показатели, отражающие мыслительные и рефлексивные процессы, условия и место событий, связанных с гневом.

\section{Обсуждение результатов}

Данное исследование является частью крупного проекта, направленного на изучение субъективного опыта психических состояний. В рамках научной школы А. О. Прохорова изучены различные аспекты психических состояний. Показана модель регуляции психических состояний, где большое внимание отводится опыту переживаний состояний. Но данная категория психического не изучена всесторонне. Имеющиеся исследования ориентированы на изучение психических состояний детей и взрослых с нормотипичным развитием. Мы поставили перед собой задачу изучить субъективный опыт психических состояний разных групп испытуемых. 
АРТИЩЕВА Л. В.

ПОЛОВОЗРАСТНЫЕ ОСОБЕННОСТИ СОДЕРЖАНИЯ СУБЪЕКТИВНОГО ОПЫТА ПСИХИЧЕСКИХ СОСТОЯНИЙ...

РосСИйскИй пСИХОЛоГИЧЕСКИЙ ЖУРнАл, 2019, Т. 16, № 4, 5-21. doi: 10.21702/rpj.2019.4.1

КОРРЕКЦИОННАЯ ПСИХОЛОГИЯ

Одна из выборок - это дети младшего и подросткового возраста с нарушениями в развитии, но с сохранным интеллектом.

Субъективный опыт психических состояний - сложная категория психического. Изучение содержания и структуры опыта состояний позволит выделить общее и специфичное в переживании состояний, а также выявить те компоненты, которые, с одной стороны, характеризуют психическое состояние, с другой стороны, могут быть маркерами в построении стратегии регуляции. Дети с нарушениями в развитии имеют слабо сформированную эмоционально-волевую сферу. И как было сказано выше, они испытывают сложности в идентификации состояний, осознании их и в узнавании, что, в свою очередь, осложняет процесс взаимодействия с окружающими, регуляции своего поведения и состояний, в налаживании взаимоотношений.

В результате анализа полученных данных мы постарались выделить те смысловые единицы субъективного опыта состояний, которые чаще встречаются в текстах испытуемых. Мы считаем, что эти компоненты, являясь чаще употребляемыми, могут составить ядерные образования опыта, а значит и стать пусковым механизмом в процессе регуляции, быть фундаментом для идентификации состояний. То есть ядерные образования, при условии их схожести в исследуемых группах, позволяют идентифицировать и дифференцировать психические состояния, свои и чужие. Периферические слои субъективного опыта представлены менее употребляемыми единицами, но именно они могут придавать разнообразие и некую специфику субъективному опыту. Ядерные и периферические слои субъективного опыта состояний мы определяли с опорой на концепцию А. О. Прохорова о семантических пространствах психических состояний, в рамках которой ядерные слои определялись путем выделения оперантов, часто встречаемых в семантических полях состояний.

Анализ данных показал, что субъективный опыт психических состояний, относящихся к разной модальности и уровню психической активности, имеет содержательную специфику в зависимости от пола и возраста. Субъективный опыт во временном континууме «прошлое - будущее» трансформируется, некоторые элементы редуцируются (уменьшается частота их употребления или/и отсутствуют). В проекции на будущее опыт представлен меньшим числом смысловых единиц. Некоторым детям было сложно представлять свое будущее и описывать состояния.

Отметим, что в каждой группе испытуемых наиболее часто встречаемым компонентом субъективного опыта является «действие/деятельность», т. е. дети раскрывают свои переживания через описание действий, поступков, занимаемой деятельности. В большей мере это свойственно младшему возрасту, что не противоречит данным исследования возрастных особенностей семантических пространств психических состояний (Прохоров, 2002). Содержательность субъективного опыта состояний у мальчиков в младшем возрасте богаче, к подростковому возрасту описания переживаний более скудные. Возможно, это связано с возрастной переоценкой многих ключевых жизненных понятий, с феноменом «ямы» (Прохоров, 2002), со снижением рефлексии и осознания в силу возрастного кризиса. У девочек выявлена обратная тенденция: к подростковому возрасту субъективный опыт состояний обогащается, большую выраженность начинают обретать смысловые единицы, отражающие чувства, эмоции, их проявления, отношения с близкими людьми, мечты и желания. В младшем возрасте субъективный опыт состояний более содержателен у мальчиков, чем у девочек. К подростковому возрасту субъективный опыт девочек становится более насыщенным и близким к опыту мальчиков.

Выявлено, что в континууме «прошлое - будущее» в субъективном опыте разномодальных психических состояний и разного уровня активности (гнев, спокойствие) встречается 
АРТИЩЕВА Л. В.

ПОЛОВОЗРАСТНЫЕ ОСОБЕННОСТИ СОДЕРЖАНИЯ СУБЪЕКТИВНОГО ОПЫТА ПСИХИЧЕСКИХ СОСТОЯНИЙ...

РосСИЙСКИЙ пСИХоЛОГИЧЕСКИЙ ЖУРнАл, 2019, Т. 16, № 4, 5-21. doi: 10.21702/rpj.2019.4.1

КОРРЕКЦИОННАЯ ПСИХОЛОГИЯ

регулятивный компонент, который носит произвольный (намеренные действия для изменения состояния) или непроизвольный характер (когда динамика состояния происходит сама по себе, но они это осознают).

В заключение отметим, что выявленная возрастная и половая специфика субъективного опыта психических состояний, выделение ядерных слоев и периферии позволят понять внутренний мир переживаний детей с ограниченными возможностями здоровья, выстраивать стратегии регуляции их психических состояний и поведения.

\section{Благодарности}

Работа выполнена при финансовой поддержке гранта РФФИ, проект № 18-013-01012 «Субъективный опыт психических состояний в ситуации прогнозирования жизнедеятельности».

\section{Литература}

Артищева, Л. В. (2018). Прошлое и будущее в субъективном опыте психических состояний детей с дефицитарным развитием. Материалы Третьей Международной научной конференции (Казанский (Приволжский) федеральный университет. 8-10 ноября 2018 г., с. 48-58). Казань: Изд-во Казанского университета.

Гарбузов, В. И. (1994). Практическая психотерапия, или как вернуть ребенку и подростку уверенность в себе, истинное достоинство и здоровье. Санкт-Петербург: Сфера.

Грибова, О. Е. (1995). К проблеме анализа коммуникации у детей с речевой патологией. Дефектология, 6, 12-19.

Дубрынина, Т. Е. и Боброва, В. В. (2017). Особенности эмоционально-волевой сферы у детей с общим недоразвитием речи дошкольного возраста. Научное сообщество студентов XXI столетия. Гуманитарные науки (с. 61-66). Новосибирск: Ассоциация научных сотрудников «Сибирская академическая книга».

Зайцева, Т. В. и Красиков, А. С. (2015). Организация психолого-педагогической коррекции. Детский дом, 15, 3-5.

Изард, К. Е. (2010). Психология эмоций. Санкт-Петербург: Питер.

Изотова, Е. К. и Никифорова, Е. В. (2004). Эмоциональная сфера ребенка: теория и практика. Москва: Академия.

Ильин, Е. П. (2013). Эмоции и чувства (2-е изд., перераб. и доп.). Санкт-Петербург: Питер.

Кондратенко, И. Ю. (2002). Особенности овладения эмоциональной лексикой детьми старшего дошкольного возраста с общим недоразвитием речи. Дефектология, 6, 51-59.

Кузнецова, Л. В., Переслени, Л. И. и Солнцева, Л. И. (2002). Основы специальной психологии: учебное пособие для студентов. Москва: Академия.

Лебединский, В.В.(2011). Нарушения психического развития в детском возрасте (6-е изд.). Москва: Академия.

Прохоров, А. О. (2002). Семантические пространства психических состояний. Дубна: Феникс+.

Прохоров, А. О. (2008). Пространственно-временная организация образа психического состояния: концептуальный аспект. Психология психических состояний: теория и практика: материалы Первой Всероссийской научно-практической конференции, Казанский государственный университет, 13-15 ноября 2008 г. Казань: Новое знание.

Прохоров, А. О. (2011). Образ психического состояния. Психология психических состояний: сборник статей (Вып. 8, с. 6-14). Казань. 
АРТИЩЕВА Л. В.

ПОЛОВОЗРАСТНЫЕ ОСОБЕННОСТИ СОДЕРЖАНИЯ СУБЪЕКТИВНОГО ОПЫТА ПСИХИЧЕСКИХ СОСТОЯНИЙ...

РосСИйскИй пСИХОЛоГИЧЕСКИЙ ЖУРнАл, 2019, Т. 16, № 4, 5-21. doi: 10.21702/rpj.2019.4.1

КОРРЕКЦИОННАЯ ПСИХОЛОГИЯ

Прохоров, А. О. (2012). Образ психического состояния: феноменологические особенности. Вопросы социальной психологии: Сб. науч. трудов (Вып. 8 (13), с. 39-51). Саратов: Наука.

Прохоров, А. О. (2013). Образ психического состояния. Психологический журнал, 34(5), $108-122$.

Саморокова, Л. А. (2015). Особенности эмоциональной сферы у детей с детским церебральным параличом младшего школьного возраста. Международный студенческий научный вестник, 6. Доступ 23 Ноября 2019, источник http://www.eduherald.ru/ru/article/view?id=13557

Холодная, М. А. (2002). Психология интеллекта. Парадоксы исследования (2-е изд.). СанктПетербург: Питер.

Холодная, М. А. (2004). Когнитивные стили. О природе индивидуального ума. Санкт-Петербург: Питер.

Шипицына, Л. М. и Волкова, Л. С. (1993). Некоторые особенности эмоционально-личностных качеств у младших школьников с общим недоразвитием речи. Дефектология, 4, 8-12.

Шкуркина, О. И. (2018). Особенности эмоционально-волевой сферы детей дошкольного возраста с общим недоразвитием речи. Молодой ученый, 27, 146-148.

Юрчук, Е. Н. (2008). Эмоциональное развитие дошкольников. Москва: Сфера.

Artishcheva, L. V. (2018). The experience of mental states of adolescents orphans. The European Proceedings of Social and Behavioural Sciences EpSBS. (Vol. XLV (45), pp. 317-325). Chelyabinsk: Future Academy.

Artishcheva, L. V. (2019). Experience of mental states in children with health disabilities. In D. Solovev (eds), Smart technologies and innovations in design for control of technological processes and objects: Economy and production. FarEastCon 2018. Smart Innovation, Systems and Technologies (Vol. 139). Springer, Cham. doi: 10.1007/978-3-030-18553-4 77

Barnfather, N., \& Amod, Z. (2012). Empathy and personal experiences of trainees in an Emotional Literacy and Persona Doll programme in South Africa. South African Journal of Psychology, 42(4), 598-607.

Barrett, L. F., Mesquita, B., Ochsner, K. N., \& Gross, J. J. (2007). The experience of emotion. Annual Review of Psychology, 58, 373-403. doi: 10.1146/annurev.psych.58.110405.085709

Duvdevany, I., Moin, V., \& Yahav, R. (2007). The social life and emotional state of adolescent children of parents who are blind and sighted: A pilot study. Journal of Visual Impairment \& Blindness, 101(3), 160-171. doi: 10.1177/0145482X0710100304

Eden, S., Romi, S., \& Braun Aviyashar, E. (2017). Being a parent's eyes and ears: emotional literacy and empathy of children whose parents have a sensory disability. JORSEN, 17(4), 257-264. doi: 10.1111/1471-3802.12383

Izard, C., Fine, S., Schultz, D., Mostow, A., Ackerman, B., \& Youngstrom, E. (2001). Emotion knowledge as a predictor of social behavior and academic competence in children at risk. Psychological Science, 12(1), 18-23. doi: 10.1111/1467-9280.00304

Kremenitzer, J. P. (2005). The emotionally intelligent early childhood educator: Self-reflective journaling. Early Childhood Education Journal, 33(1), 3-9. doi: 10.1007/s10643-005-0014-6

Конфликт интересов отсутствует 